\title{
Median Nerve Somatosensory Evoked Potential in HTLV-I Associated Myelopathy
}

\author{
Reza Boostani ${ }^{1}$, Ali Poorzahed ${ }^{2}$, Zahra Ahmadi $^{3}$, Ali Mellat ${ }^{4}$
}

\author{
${ }^{1}$ Associate Professor of Neurology, Department of Neurology, Faculty of Medicine, Mashhad University of Medical \\ Sciences, Mashhad, Iran \\ ${ }^{2}$ Neurologist, Department of Neurology, Faculty of Medicine, Mashhad University of Medical Sciences, Mashhad, \\ Iran \\ ${ }^{3}$ Resident of Neurology, Department of Neurology, Faculty of Medicine, Mashhad University of Medical Sciences, \\ Mashhad, Iran \\ ${ }^{4}$ Assistant Professor of Neurology, Department of Neurology, Faculty of Medicine, Shahid Sadoughi University of \\ Medical Sciences, Yazd, Iran
}

Type of article: Original

\begin{abstract}
Introduction: HTLV-I Associated Myelopathy/Tropical Spastic Paraparesis (HAM/TSP) is a progressive Myelopathy that mainly involves the corticospinal tract. Despite pronounced involvement of the lower limbs, patients also have abnormalities in their upper limbs. So, we studied somatosensory-evoked potentials (SSEPs) of the median nerve in HAM/TSP patients to determine the extent of the involvement of the pathway of the central nervous system, especially the cervical spinal cord.

Methods: In this cross sectional study, 48 patients with HAM/TSP who were referred to Qaem Hospital in Mashhad from October 2010 to October 2011 were evaluated for various indices, including SSEPs of the median nerve for $\mathrm{N}_{9}, \mathrm{~N}_{11}, \mathrm{~N}_{13}$, and $\mathrm{N}_{20}$ waveforms and also $\mathrm{N}_{11-13}$ and $\mathrm{N}_{13-20}$ Inter Peak Latency (IPL), severity of disease (based on Osama criteria), disease duration (less or more than 2 years), age, and gender. SPSS software was used for data analysis. The t-test was used for quantitative data, and the chi-squared test was used for the qualitative variables.

Results: Thirty-four patients (70.2\%) were females. The mean age was $45.6 \pm 14.2$ years. About SSEPs indices of the median nerve, $\mathrm{N}_{9}$ and $\mathrm{N}_{11}$ were normal in all patients, but $\mathrm{N}_{13}(50 \%), \mathrm{N}_{20}(16.7 \%)$, IPL $\mathrm{L}_{11-13}(58.3 \%)$, and $\mathrm{IPL}_{13-20}(22.9 \%)$ were abnormal. No significant relationships were found between age, gender, disease duration, and SSEPs indices $(\mathrm{p}>0.05)$, but IPL $\mathrm{IL}_{11-13}$ and IPL $\mathrm{I}_{13-20}$ had significant relationships with disease disability $(\mathrm{p}=$ 0.017 and $\mathrm{p}=0.01$, respectively).

Conclusion: Despite the lack of obvious complaints of upper limbs, SSEPs indices of the median nerve from the cervical spinal cord to the cortex were abnormal, which indicated extension of the lesion from the thoracic spinal cord up to the cervical spinal cord and thalamocortical pathways. Also, abnormalities in the cervical spinal cord had a direct correlation with the severity of disability in patients with HAM/TSP.
\end{abstract}

Keywords: HTLV-I, HAM/TSP, SSEPs, Spinal Cord

\section{Introduction}

The Human T-lymphotropic virus Type I (HTLV-1) is a retrovirus that accounts for several human diseases (1-7). Two of the most frequent diseases induced by HTLV-I are Adult T-cell Leukemia/Lymphoma (ATLL) (8) and chronic progressive myelopathy, called HTLV-I Associated Myelopathy/Tropical Spastic Paraparesis (HAM/TSP) (2). Individuals are at higher risk in endemic regions of the world, including Iran and Khorasan Province in particular (9). HAM/TSP is described as the gradual onset of slowly progressive myelopathy, which predominately involves the corticospinal tract and is presented by sensory, motor, and urinary function impairments $(10,11)$. The diagnosis is based on clinical findings corroborated with detection of HTLV-I antibodies in serum and cerebrospinal

\section{Corresponding author:}

Dr. Ali Mellat, Department of Neurology, Faculty of Medicine, Shahid Sadoughi University of Medical Sciences, Yazd, Iran. Tel: +98.353183802, Fax:+98.353183802, Email: Ali_mellat@ssu.ac.ir Received: November 17, 2015, Accepted: February 11, 2016, Published: May 2016 iThenticate screening: February 11, 2016, English editing: April 16, 2016, Quality control: May 03, 2016 (C) 2016 The Authors. This is an open access article under the terms of the Creative Commons Attribution-NonCommercialNoDerivs License, which permits use and distribution in any medium, provided the original work is properly cited, the use is non-commercial and no modifications or adaptations are made. 
fluid (CSF) (12). Polymerase chain reaction (PCR) can be used on peripheral blood and CSF cells of infected individuals as well (13). Expansion and infiltration of immunocompetent mononuclear cells directed against viral antigens on the surface of infected T-cells in CNS section might be responsible for the pathology of HAM/TSP (14). Numerous electrophysiological studies have been administered to elucidate and establish the extent of CNS involvement in patients with HAM/TSP (15-18). Somatosensory evoked potentials (SSEPs) are a series of waves that reflect the sequential activation of neural structures along the somatosensory ascending tracts. Suga et al. (1999) showed that the central motor and sensory conduction times were abnormal in patients with HAM/TSP (19). Despite the fact that HAM/TSP typically affects the lower extremities, corresponding neurological abnormalities of the upper extremities (i.e., pathologic hyper reflexia) (20) are seen in a minority of patients; therefore, we conducted this study to determine the extent of the central nervous system's engagement, particularly the cervical spinal cord, in HAM/TSP patients by obtaining somatosensory evoked potentials (SSEPs) of the median nerve.

\section{Material and Methods}

Our cross sectional study was performed on 48 patients with HAM/TSP who were referred to the Neurology Department at Qaem Hospital in Mashhad, Iran, from October 2010 to October 2011. Various indices were measured for each SSEP recording, including disease severity based on Osame criteria (21) and duration of the disease, age, and gender. SSEP of the median nerve also were registered and $\mathrm{N}_{9}, \mathrm{~N}_{11}, \mathrm{~N}_{13}, \mathrm{~N}_{20}$ conduction latencies, as well as $\mathrm{N}_{11-\mathrm{N} 13}$ and $\mathrm{N}_{13-\mathrm{N} 20}$ Interpeak latencies (IPLs) were measured for each SSEP recording. Inclusion benchmarks were restricted to known cases of HAM/TSP according to the World Health Organization's (WHO's) diagnosis guidelines. None of the patients was paraparetic or myelopathic due to non-HTLV-I origins, and they had no coexisting causes of myelopathy, such as HIV, Multiple Sclerosis, Vitamin $\mathrm{B}_{12}$ deficiency, or compressive sources. Informed consent was obtained from all subjects, and the Hospital's Ethics Committee approved the study protocol. All patients underwent a comprehensive evaluation, which consisted of a medical history and clinical examination, serum and CSF analysis by Enzyme-Linked Immunosorbent Assay (ELISA) and polymerase chain reaction (PCR) to confirm the disease. In addition, MRI of the brain and spinal cord and further laboratory tests were performed to rule out other causes of spastic paraparesia. Subsequently, median nerve SSEPs were elicited from confirmed HAM/TSP patients utilizing a Nihon Kohden electromyography machine. The stimulus intensity ranged from 10 to 30 milliamperes. The stimulus frequency was 3-6 Hertz, and the frequency bandpass filter was set at 52000 Hertz. SPSS version 16 (SPSS, Inc., Chicago, Illinois, USA) was used for statistical analysis. The t-test was used for quantitative data, and the chi-squared test was used for the qualitative variables, with a value of $p<0.05$ being considered significant.

\section{Results}

All of the confirmed HAM/TSP patients were subjected to clinical evaluation in the form of detailed history and a thorough physical examination, and, afterwards, recordings of median nerve SSEPs was performed on all of the cases. The initial sample had 53 patients, but five patients were excluded due to prolonged latency of $\mathrm{N}_{9}$, which is an indicator of peripheral nerve involvement. Consequently, 48 patients were enrolled in the study, six of whom had a duration of the disease less than two years, and the remaining patients had been afflicted by the disease for more than two years. The patients included in this study had a mean age of $45.6 \pm 14.2$ years, and $34(70.2 \%)$ of them were females. There was a positive family history for HAM/TSP in 12 of the patients $(25 \%)$. Forty-eight (100\%) of the patients had a history of breastfeeding for more than one year, $20(41.7 \%)$ of them had at least one major surgery, and $2(4.2 \%)$ had a history of blood transfusion. Our patients were more likely to report complaints of abnormal gait and leg weakness (34 patients) and lower limb paresthesia and numbness (6 patients), while the rest had other complaints. Considering urinary manifestations, 28 were suffering from increased urinary frequency, 6 from urgency, and 10 from urinary incontinency. Four patients had no urinary complaints. None of the patients had cutaneous, ophthalmic or hematologic signs or symptoms, and the neurological examination of cranial nerves and cerebellum failed to show any abnormalities; however, 3 patients had abnormalities of the autonomic nervous system. According to Osame Motor Disability Grading (MDG), the mean MDG was $3.2 \pm 1.4$ in our study group (ranging from 1 to 5 with a mode of 3 ). Table 1 summarizes the findings from the sensory and motor examination of extremities. On the MRI of brain and cervical spine, performed with a 1.5 tesla MRI scanner, no significant lesions were observed in 45 patients, while 3 patients showed $1-3$ small $(<1 \mathrm{~cm})$ cerebral white matter lesions. SSEP measurements of median nerve elicited from patients are shown on Table 2 . The normal $\mathrm{N}_{9}$ component in all subjects implied that the peripheral nervous system was intact, denoting nonparticipation of the median nerve. Also, severe abnormal $\mathrm{N}_{11-13}$ ILP signifies engagement of cervical spinal cord. Table 3 shows the effect of gender and duration of the disease, and Table 4 shows the effect of age and disease disability (according to Osame MDG) all on median nerve SSEP components. There was no remarkable correspondence between the different parameters of 
SSEPs with duration of disease, age, or gender of the patients, but there was a statistically significant correlation between the disease disability and each of the $\mathrm{N}_{11-13}$ ILPs and $\mathrm{N}_{13-20}$ ILPs.

Table 1. Abnormal findings in neurologic examination [n (\%)]

\begin{tabular}{|l|l|l|}
\hline Abnormal findings in neurologic examination & Upper extremities & Lower extremities \\
\hline Deep Vibration Sensory Abnormality & 0 & $20(41.7)$ \\
\hline Deep Position Sensory Abnormality & 0 & $24(50)$ \\
\hline Superficial Sensory Abnormality & 0 & 0 \\
\hline Babinski Sign or Hoffman sign* & $46(95.8)$ & $46(95.8)$ \\
\hline$\uparrow$ Deep Tendon Reflex & $46(95.8)$ & $48(100)$ \\
\hline$\downarrow$ Muscle force & 0 & $24(50)$ \\
\hline$\uparrow$ Muscle tone & $8(16.7)$ & $36(75)$ \\
\hline
\end{tabular}

*Babinski Sign in lower extremities and Hoffman sign in upper extremities

Table 2. SSEPs indices of Median Nerve: Mean \pm Standard Deviation and frequency of abnormal indices are shown

\begin{tabular}{|l|l|l|l|l|l|l|}
\hline Index & $\mathrm{N}_{9}$ & $\mathrm{~N}_{11}$ & $\mathrm{~N}_{13}$ & $\mathrm{~N}_{20}$ & IPL N $\mathrm{N}_{11-13}$ & IPL N $\mathrm{N}_{13-20}$ \\
\hline Mean \pm SD & $9.3 \pm 0.5$ & $11.6 \pm 1.0$ & $15.6 \pm 1.9$ & $21.5 \pm 1.3$ & $4.0 \pm 1.4$ & $5.9 \pm 2.5$ \\
(Normal Values) & $(10.8)$ & $(13.2)$ & $(15.5)$ & $(21.7)$ & $(3.1)$ & $(7.4)$ \\
\hline Abnormal [n (\%)] & 0 & 0 & $24(50 \%)$ & $8(16.7 \%)$ & $28(58.3 \%)$ & $11(22.9 \%)$ \\
\hline
\end{tabular}

Table 3. Comparison the frequency of abnormal Median SSEPs indices based on Gender and Disease duration

\begin{tabular}{|l|l|l|l|l|l|l|}
\hline \multirow{2}{*}{ Index } & Gender & \multicolumn{4}{|l|}{ Disease Duration } \\
\cline { 2 - 7 } & Female & Male & p-value & $<2$ years & $>2$ years & p-value \\
\hline $\mathrm{N}_{9}$ & 0 & 0 & 1 & 0 & 0 & 1 \\
\hline $\mathrm{N}_{11}$ & 0 & 0 & 1 & 0 & 0 & 1 \\
\hline $\mathrm{N}_{13}$ & 16 & 8 & 0.52 & 2 & 22 & 0.66 \\
\hline $\mathrm{N}_{20}$ & 2 & 6 & 0.002 & 3 & 5 & 0.05 \\
\hline IPL N $11-13$ & 20 & 8 & 0.915 & 2 & 26 & 0.22 \\
\hline IPL N $\mathrm{N}_{13-20}$ & 7 & 4 & 0.55 & 2 & 9 & 0.61 \\
\hline
\end{tabular}

Notes: All females $=34$; All men $=14 ; 6$ patients had disease duration less than 2 years, and 42 patients had disease duration more than 2 years.

Table 4. Correlations between Age, Disability and indices of median nerve SSEPs

\begin{tabular}{|l|l|l|l|l|l|l|}
\hline Index & $\mathrm{N}_{9}$ & $\mathrm{~N}_{11}$ & $\mathrm{~N}_{13}$ & $\mathrm{~N}_{20}$ & IPL N $_{11-13}$ & IPL N \\
\hline Age (p-value) & 0.245 & 1 & 0.629 & 0.339 & 0.726 & 0.248 \\
\hline Disability (p-value) & 0.144 & 1 & 0.055 & 0.425 & 0.017 & 0.010 \\
\hline
\end{tabular}

\section{Discussion}

HTLV-I infection is lifelong and up to $4 \%$ of those infected will progress to HAM/TSP with higher prevalence in females (22). Minimum age of patients in our study was 17, but, according to prior studies, it can occur at any age and, similar to our data, it is usually diagnosed in the fourth to fifth decade of life (23). Objective sensory examination did not reveal any superficial or deep sensory loss in upper extremities but abnormal deep tendon reflexes, hyper tonicity, and positive Hoffman's sign were detected in almost all patients. These abnormal findings in the upper extremities were considered in earlier studies, and they suggest the possible involvement of the cervical spinal cord and cerebral cortex in the course of the disease (20). In our study, $\mathrm{N}_{9}$ and $\mathrm{N}_{11}$ components of SSEPs, which represent brachial plexus and dorsal root entry zone, respectively, were in normal limitation in all patients, showing that the peripheral nervous system was unimpaired in the HAM/TSP patients. In contrast, cervical components of SSEP, which are $\mathrm{N}_{13}$ and $\mathrm{N}_{11-13}$ IPL, were abnormal in almost $50 \%$ of the patients, demonstrating that the cervical cord, particularly the dorsal column, is involved in this disease. Also, abnormalities were found in the $\mathrm{N}_{20}$ and $\mathrm{N}_{13-20}$ conduction latencies of approximately $20 \%$ of patients are compatible with thalamocortical engagement, which is beneficial to demonstrate the pathophysiology of disease and its expansion in CNS. A study performed by Shimizo et al. on 13 patients with HAM/TSP reported significant prolonged central motor conduction time (CMCT) both in upper and lower extremities, and central sensory conduction time (CSCT) of only lower extremities (24). Also the CMCTs were prolonged to a greater extent compared to CSCTs in both upper and lower extremities. In an earlier study by Suga and colleagues, impairment of CMCTs was found in the upper (17.6\%) and lower $(72.8 \%)$ extremities, and the CSCTs in the lower extremities were abnormal in $31.3 \%$ of patients, while 
CSCTs in the upper limbs were normal (19). CSCT findings of upper extremities in this latter study conflict with our view on engagement of thalamocortical pathways and dorsal column of cervical spinal cord; therefore, we suggest further investigations using a larger number of patients. In a study by Kakigi et al. on 19 patients, $\mathrm{N}_{13}$ and $\mathrm{N}_{20}$ conduction latencies in 3 patients and $\mathrm{N}_{9-13}$ IPLs in 9 patients were significantly prolonged, indicating subclinical abnormalities in posterior column similar to our study; and the finding of prolonged $\mathrm{P}_{400}$ and $\mathrm{P}_{37}$ latencies in posterior tibialis nerve SSEPs supports our notion that cerebral white matter, cortex, and thalamocortical pathways are involved in the HAM/TSP process (25). In our study, age, gender, and duration of disease had no remarkable effect on SSEP parameters. This corroborates the findings of Suga who could not find any correlation between duration of disease and SSEP latencies, demonstrating that damage to cervical spinal cord occurs in early stages of the disease ${ }^{19}$. In this study, we found a significant correlation between prolongation of $\mathrm{N}_{11-13}$ and $\mathrm{N}_{13-20}$ IPLs and severity of disease disability, which was in accordance with Shimizu et al.'s observations (24); however, Suga and colleagues reported no meaningful correlation between the severity of disabilities and either CMCTs or CSCTs of the lower extremities (19). Also, no statistically significant correlation between abnormal CMCTs and hyper reflexia in upper extremities was recorded in Suga et al.'s study (19). These findings might be due to peripheral axonal damage that occurs to a greater extent in the lower extremities and may lead to decreased sensitivity of recorded CMCTs and CSCTs. We demonstrated that the increase in $\mathrm{N}_{11-13}$ and $\mathrm{N}_{13-20}$ IPLs in accordance with severity of disabilities was directly correlated with the degree of spinal cord damage. A major limitation of the study could be described as insufficient cooperation of the patients for performing the SSEP study, presumably resulting in an undesirable sample size.

\section{Conclusions}

Despite the lack of obvious upper limb complaints in patients with HAM/TSP, SSEP of median nerve from cervical spinal cord to cortex were abnormal, indicating expansion of the lesion from the thoracic spinal cord up to the cervical spinal cord and thalamocortical pathways. We also demonstrated that abnormalities in the cervical spinal cord have a direct correlation with the severity of disability in patients with HAM/TSP; however, further studies are recommended to confirm these findings. The practical implication of the present study can be defined as a valuable step forward in illustrating the demyelination process of the central nervous system through SSEP, the process that typically eludes MR imaging.

\section{Acknowledgments:}

The authors express their sincere gratitude to the staff in the Research Department of MUMS for their sponsorship.

\section{Conflict of Interest:}

There is no conflict of interest to be declared.

\section{Authors' contributions:}

All authors contributed to this project and article equally. All authors read and approved the final manuscript.

\section{References:}

1) Poiesz BJ, Ruscetti FW, Gazdar AF, Bunn PA, Minna JD, Gallo RC. Detection and isolation of type C retrovirus particles from fresh and cultured lymphocytes of a patient with cutaneous T-cell lymphoma. Proc Natl Acad Sci U S A. 1980; 77(12): 7415-9. doi: 10.1073/pnas.77.12.7415, PMID: 6261256, PMCID: PMC350514.

2) Gessain A, Barin F, Vernant JC, Gout O, Maurs L, Calender A, et al. Antibodies to human T-lymphotropic virus type-I in patients with tropical spastic paraparesis. Lancet. 1985; 2(8452): 407-10. doi: 10.1016/S0140-6736(85)92734-5, PMID: 2863442.

3) LaGrenade L, Hanchard B, Fletcher V, Cranston B, Blattner W. Infective dermatitis of Jamaican children: a marker for HTLV-I infection. Lancet. 1990; 336(8727): 1345-7. doi: 10.1016/0140-6736(90)92896-P, PMID: 1978165.

4) Inose M, Higuchi I, Yoshimine K, Suehara M, Izumo S, Arimura K, et al. Pathological changes in skeletal muscle in HTLV-I-associated myelopathy. J Neurol Sci. 1992; 110(1-2): 73-8. doi: 10.1016/0022510X(92)90012-A, PMID: 1506872.

5) Sowa JM, Human T. lymphotropic virus I, myelopathy, polymyositis and synovitis: an expanding rheumatic spectrum. J Rheumatol. 1992; 19(2): 316-8. PMID: 1629837.

6) Kawai H, Inui T, Kashiwagi S, Tsuchihashi T, Masuda K, Kondo A, et al. HTLV-I infection in patients with autoimmune thyroiditis (Hashimoto's thyroiditis). J Med Virol. 1992; 38(2): 138-41. doi: 10.1002/jmv.1890380212, PMID: 1460458. 
7) Kimura I. [HABA (HTLV-I associated bronchiolo-alveolar disorder)].Nihon KyobuShikkan Gakkai Zasshi. 1992; 30(5): 787-95. PMID: 1630042.

8) Miyoshi I, Miyamoto K, Sumida M, Nishihara R, Lai M, Yoshimoto S, et al. Chromosome 14q+ in adult Tcell leukemia. Cancer Genet Cytogenet. 1981; 3(3): 251-9. doi: 10.1016/0165-4608(81)90092-3, PMID: 6974589.

9) Abbaszadegan MR, Gholamian M, Tabatabaee A, Farid R, Houshmand M, Abbaszadegan M. Prevalence of human T-lymphotropic virus type 1 among blood donors from mashhad, Iran. J Clin Microbiol. 2003; 41: 2593-5. doi: 10.1128/jcm.41.6.2593-2595.2003, PMID: 12791885, PMCID: PMC156501.

10) Osama M, Matsumoto M, Usuku K, Izumo S, Ijichi N, Amitani H, et al. Chronic progressive myelopathy associated with elevated antibodies to human T-lymphotropic virus type I and adult T-cell leukemialike cells. Ann Neurol. 1987; 21(2): 117-22. doi: 10.1002/ana.410210203, PMID: 2881513.

11) Osama M, Usuku K, Izumo S, Ijichi N, Amitani H, Igata A, et al. HTLV-I associated myelopathy, a new clinical entity. lancet. 1986; 1(8488): 1031-2. PMID: 2871307.

12) Gessain A, Caudie C, Gout O, Vernant JC, Maurs L, Giordano C, et al. Intrathecal synthesis of antibodies to human $\mathrm{T}$ lymphotropic virus type I and the presence of IgG oligoclonal bands in the cerebrospinal fluid of patients with endemic tropical spastic paraparesis. J Infect Dis. 1988; 157(6): 1226-34. doi: 10.1093/infdis/157.6.1226, PMID: 2897399.

13) Iannone R, Sherman MP, Rodgers-Johnson PE, Beilke MA, Mora CA, Amin RM, et al. HTLV-I DNA sequences in CNS tissue of a patient with tropical spastic paraparesis and HTLV-I-associated myelopathy. J Acquir Immune Defic Syndr. 1992; 5(8): 810-6. doi: 10.1097/00126334-199208000-00007, PMID: 1517966.

14) Iwasaki Y. Pathology of chronic myelopathy associated with HTLV-I infection (HAM/TSP). J Neurol Sci. 1990; 96(1): 103-23. doi: 10.1016/0022-510X(90)90060-Z, PMID: 2351985.

15) Arimura K, Rosales R, Osama M, Igata A. Clinical electrophysiologic studies of HTLV-I-associated myelopathy. Arch Neurol. 1987; 44(6): 609-12. doi: 10.1001/archneur.1987.00520180033012, PMID: 2883963.

16) Ugawa Y, Kohara N, Shimpo T, Mannen T. Central motor and sensory conduction in adrenoleukomyeloneuropathy, cerebrotendinous xanthomatosis, HTLV-1-associated myelopathy and tabesdorsalis. J Neurol Neurosurg Psychiatry. 1988; 51(8): 1069-74. doi: 10.1136/jnnp.51.8.1069, PMID: 2851031, PMCID: PMC1033116.

17) Moritoyo H, Arimura K, Arimura Y, Tokimura Y, Rosales R, Osama M. Study of lower limb somatosensory evoked potentials in 96 cases of HTLV-I-associated myelopathy/tropical spastic paraparesis. J Neurol Sci. 1996; 138(1-2): 78-81. doi: 10.1016/0022-510X(95)00351-2, PMID: 8791242.

18) Young RE, Morgan OS, Forster A. Motor pathway analysis in HAM/TSP using magnetic stimulation and F-waves. Can J Neurol Sci. 1998; 25(1): 48-54. doi: 10.1017/S0317167100033485, PMID: 9532281.

19) Suga R, Tobimatsu S, Kira J, Kato M. Motor and somatosensory evoked potential findings in HTLV-I associated myelopathy. J Neurol Sci. 1999; 167(2): 102-6. doi: 10.1016/S0022-510X(99)00148-3.

20) Boostani R, Mellat Ardekani A, Ashrafi H. Khorasan Disease: Prevalence of HTLV-I Associated Myelopathy/Tropical Spastic Paraparesis (HAM/TSP) In West Azarbaijan from 2004 to 2007. Iran Red Crescent Med J. 2011; 13(6): 428-30. PMID: 22737507, PMCID: PMC3371933.

21) Nakagawa M, Izumo S, Ijichi S, Kubota H, Arimura $K$, Kawabata $M$, et al. HTLV-I-associated myelopathy: analysis of 213 patients based on clinical features and laboratory findings. J Neurovirol. 1995; 1(1): 50-61. doi: 10.3109/13550289509111010, PMID: 9222342.

22) Orland JR, Engstrom J, Fridey J, Sacher RA, Smith JW, Nass C, et al. Prevalence and clinical features of HTLV neurologic disease in the HTLV Outcomes Study. Neurology. 2003; 61(11): 1588-94. doi: 10.1212/01.WNL.0000096011.92542.DA, PMID: 14663047.

23) Quintas S, Moreno T, Lobo-Antunes N, Levy-Gomes A. [Tropical spastic paraparesis and HTLV-I associated myelopathy in infancy. A case report and review of the literature]. Rev Neurol. 2004; 39(12): 1133-6. PMID: 15625631.

24) Shimizu H, Shiga Y, Fujihara K, Ohnuma A, Itoyama Y. Clinical and physiological significance of abnormally prolonged central motor conduction time in HAM/TSP. J Neurol Sci. 2001; 185(1): 39-42. doi: 10.1016/S0022-510X(01)00455-5, PMID: 11266689.

25) Kakigi R, Kuroda Y, Takashima H, Endo C, Neshige R, Shibasaki H. Physiological functions of the ascending spinal tracts in HTLV-I-associated myelopathy (HAM). Electroencephalogr Clin Neurophysiol. 1992; 84(2): 110-4. doi: 10.1016/0168-5597(92)90015-4, PMID: 1372225. 